\title{
Functional significance of co-occurring mutations in PIK3CA and MAP3K1 in breast cancer
}

\author{
Alvaro Avivar-Valderas ${ }^{1,4}$, Robert McEwen ${ }^{1}$, Amir Taheri-Ghahfarokhi², Larissa S. \\ Carnevalli ${ }^{3}$, Elizabeth L. Hardaker ${ }^{3}$, Marcello Maresca ${ }^{2}$, Kevin Hudson ${ }^{3,5}$, Elizabeth \\ A. Harrington ${ }^{1}$ and Francisco Cruzalegui ${ }^{1,6}$ \\ ${ }^{1}$ Translational Science, Oncology, IMED Biotech Unit, AstraZeneca, Cambridge, UK \\ ${ }^{2}$ Translational Genomics, Discovery Sciences, IMED Biotech Unit, AstraZeneca, Gothenburg, Sweden \\ ${ }^{3}$ Bioscience, Oncology, IMED Biotech Unit, AstraZeneca, Cambridge, UK \\ ${ }^{4}$ Current address: TiGenix, Parque Tecnológico de Madrid, Tres Cantos, Madrid, Spain \\ ${ }^{5}$ Current address: 2TheNth, Adelphi Mill, Bollington, Macclesfield, UK \\ ${ }^{6}$ Current address: Pierre Fabre R\&D Centre, Toulouse, France \\ Correspondence to: Alvaro Avivar-Valderas, email: alvaro.avivar@tigenix.com \\ Keywords: luminal A; breast cancer; PIK3CA; MAP3K 1; CRISPR gene editing \\ Received: February 05, $2018 \quad$ Accepted: March 22, $2018 \quad$ Published: April 20, 2018 \\ Copyright: Avivar-Valderas et al. This is an open-access article distributed under the terms of the Creative Commons Attribution \\ License 3.0 (CC BY 3.0), which permits unrestricted use, distribution, and reproduction in any medium, provided the original author \\ and source are credited.
}

\section{ABSTRACT}

The PI3Ka signaling pathway is frequently hyper-activated in breast cancer (BrCa), as a result of mutations/amplifications in oncogenes (e.g. HER2), decreased function in tumor suppressors (e.g. PTEN) or activating mutations in key components of the pathway. In particular, activating mutations of PIK3CA ( 45\%) are frequently found in luminal A BrCa samples. Genomic studies have uncovered inactivating mutations in MAP3K1 (13-20\%) and MAP2K4 ( 8\%), two upstream kinases of the JNK apoptotic pathway in luminal A BrCa samples. Further, simultaneous mutation of PIK3CA and MAP3K1 are found in 11\% of mutant PIK3CA tumors. How these two alterations may cooperate to elicit tumorigenesis and impact the sensitivity to PI3K and AKT inhibitors is currently unknown. Using CRISPR gene editing we have genetically disrupted MAP3K1 expression in mutant PIK3CA cell lines to specifically create in vitro models reflecting the mutational status of PIK3CA and MAP3K1 in

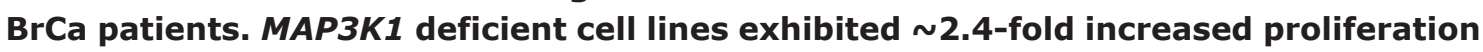
rate and decreased sensitivity to PI3Ka/ठ(AZD8835) and AKT (AZD5363) inhibitors ( 2.61 and $\sim 5.23$-fold IC $_{50}$ increases, respectively) compared with parental control cell lines. In addition, mechanistic analysis revealed that MAP3K1 disruption enhances AKT phosphorylation and downstream signaling and reduces sensitivity to AZD5363mediated pathway inhibition. This appears to be a consequence of deficient MAP3K1JNK signaling increasing IRS1 stability and therefore promoting IRS1 binding to p85, resulting in enhanced PI3Ka activity. Using 3D-MCF10A-PI3Ka ${ }^{\mathrm{H1047R}}$ models, we found that MAP3K1 depletion increased overall acinar volume and counteracted AZD5363mediated reduction of acinar growth due to enhanced proliferation and reduced apoptosis. Furthermore, in vivo efficacy studies revealed that MAP3K1-deficient MCF7 tumors were less sensitive to AKT inhibitor treatment, compared with parental MCF7 tumors. Our study provides mechanistic and in vivo evidence indicating a role for MAP3K1 as a tumor suppressor gene at least in the context of PIK3CA-mutant backgrounds. Further, our work predicts that MAP3K1 mutational status may be considered as a predictive biomarker for efficacy in PI3K pathway inhibitor trials. 


\section{INTRODUCTION}

$\mathrm{BrCa}$ is characterized by its heterogeneity $[1,2]$. Traditionally classified according to histological criteria, $\mathrm{BrCa}$ has also been categorized according to gene expression and recently according to genomic alterations. Large-scale DNA sequencing [3-5] has provided a mutational landscape of $\mathrm{BrCa}$. One of the most prevalent genes mutated in cancer is PIK3CA which is mutated in $45 \%$ of luminal A BrCa cases [3]. Multiple drug-discovery organizations have been developing PI3K $\alpha$ inhibitors for many years but response rates are low and no drug against this target has yet been approved. We hypothesized that perhaps response rates are low because other mediators that are frequently mutated in conjunction with PIK3CA may counteract the effect of PI $3 \mathrm{~K} \alpha$ inhibitors and other PI3K pathway inhibitors, promoting resistance. Thus, we interrogated published genomic databases to identify genes that were frequently mutated in $\mathrm{BrCa}$ patients with mutant PIK3CA ( $m P I K 3 C A)$. In addition to genes previously reported to have a role in $\mathrm{BrCa}$ some novel genes were identified in those studies [3]. Because of the frequency of co-occurrence with $M P I K 3 C A$ we were particularly interested in MAP $3 K 1$ and $M A P 2 K 4$, two upstream kinases of the JNK apoptotic pathway. In particular, mutations in MAP3K1 are found in $13-20 \%$ of luminal $\mathrm{A} \mathrm{BrCa}$. The majority of these are loss of function (LoF) mutations suggesting a tumor suppressor role for this kinase [3,5]. However despite this genomic evidence, the role of $M A P 3 K 1$ in tumorigenesis is not completely clear, since while several studies support the notion of $M A P 3 K 1$ having a tumor suppressor role [4, 6-9], others have reported that $M A P 3 K 1$ fuels tumor progression and metastasis [9-11].

MAP3K1 or MEKK1 (MEK kinase 1) is a serine-threonine kinase of $196 \mathrm{kDa}$ [12] belonging to the mitogen-activated protein kinase kinase kinase 1 (MAP3K) family $[12,13]$. MAP3K1 is activated by a variety of stimuli (e.g. growth factors, cytokines) and cell stresses (e.g. loss of adhesion, microtubule disruption, cold temperature). Of the 19 members of the MAP3K family, MAP3K1 is the only member of the group which contains specific domains (PHD, SWIN and RING motifs) and features (caspase cleavage site and E3 ligase activity) $[7,14,15]$. Caspase- 3 targeting of MAP3K1 produces a $91 \mathrm{kDa}$ c-terminal catalytic fragment that localizes in the cytoplasm and has selectivity toward JNK but not to ERK1/2 and is thought to play a role in the induction of apoptosis [16]. By virtue of transducing pro-apoptotic and pro-survival signaling via caspase-3 and ERK/NF- $\mathrm{\kappa B}[17$, 18], respectively, MAP3K1 appears to play a critical role in balancing cell fate decisions $[13,19,20]$.

Currently, there is limited understanding of the cross-talk between PI3K $\alpha$ and MAP3K1 signal transduction pathways. AKT has been reported to suppress stress-induced activation of the MAP3K1-MAP2K1-JNK axis preventing apoptosis induction [21]. Hyperactivation of AKT inhibits JNK activity but not MAP3K1, suggesting that cross-talk happens at the level of MAP2K1, and indeed it was demonstrated that AKT is able to bind and phosphorylate MAP2K1 [21]. In addition, several lines of evidence suggest that JNK can cross-talk with the PI3K pathway [22-24], for example via insulin receptor substrate-1 (IRS1). Serine phosphorylation of IRS1 by JNK inhibits its activity by promoting IRS1 degradation via the proteasome; such phosphorylation can also be transduced by mTOR downstream target $\mathrm{p} 70[25,26]$.

In this study we aimed to identify proteins with a relevant role in the cross-talk of PI3K and MAP3K1 pathways. The high rate of MAP3K1 LoF mutations in ER-positive $\mathrm{BrCa}$ patients (frequently $m P I K 3 C A$ ) suggest that pathway cross-talk might be important in tumorigenesis or response to anti-cancer therapeutics. Our work aimed to characterize whether LoF mutations in MAP3K1 provide selective advantage for tumor progression and how this impacts on resistance to PI3K pathway targeted therapies.

\section{RESULTS}

\section{MAP3K1 depletion activates the PI3K pathway and reduces sensitivity to PI3K pathway inhibitors}

In an attempt to understand the relationship between $P I K 3 C A$ and MAP $3 K 1$ and the clinical relevance of the mutational status of these genes we interrogated published genomic databases [3-5]. Using the TCGA database we found that PIK3CA and MAP3KI are mutated in $36 \%$ and $9 \%$ respectively in a cohort of $\mathrm{BrCa}$ patients (Supplementary Figure 1A). We observed a high incidence of these mutations within the luminal A subgroup [4] and noted high frequency of co-occurring MAP3K1 and PIK3CA mutational events (Supplementary Figure $1 \mathrm{~A})$. Indeed, previous genomic analysis has predicted a positive correlation between MAP3K1 and PIK3CA mutations supporting a case functional cooperation [4]. Further, with the exception of arginine-273 and isoleucine-761 frameshift mutations, found in 3 samples in TCGA and 1 in the Ellis et al. study [4], there were no distinct hot-spot mutation sites within the MAP3K1 domains (Supplementary Figure 1A). Instead, mutations in $M A P 3 K 1$ were distributed through the different domains of the gene.

We set out to test the hypothesis that MAP3K1 inactivation or depletion has an impact on the activity of the PI3K pathway and the functional activity of inhibitors of this pathway. However, we were confronted with a lack of established tumor cell models containing both activating $m P I K 3 C A$ and inactivating $M A P 3 K 1$ alterations. To overcome this lack of models we decided to deplete endogenous levels of MAP3K1 in BrCa cell lines already 
containing $m P I K 3 C A$. We considered gene depletion to be a surrogate model for $M A P 3 K 1 \mathrm{LoF}$ mutations in tumors, since the majority of $M A P 3 K 1$ genomic mutations found in cancer patients are scattered frame-shifts insertions/ deletions [3, 4] and large chromosomal deletions [5] (i.e. LoF mutations). Then, we used such models to assess the impact of $M A P 3 K 1$ mutations on the response to PI3K pathway inhibitors (AZD8835 [27] and AZD5363 $[28,29])$.

Firstly, using siRNA, we reduced $M A P 3 K 1$ expression in two PIK3CA-mutant tumor cell lines (MCF7 and T47D) and in a breast cell line (MCF10A) that had been genetically engineered to express a common PIK3CA (H1047R) mutant (hereafter referred to as MCF10A-PI3K $\left.\alpha^{\mathrm{H} 1047 \mathrm{R}}\right)$. In scrambled control RNA (scRNA) treated cells, following treatment with PI3K $\alpha / \delta$ inhibitor AZD8835 [27] we observed a significant increase in the expression levels of MAP3K1 in all cell lines. Also, siRNA targeting of $M A P 3 K 1$ resulted in an increase in pAKT (T308) levels; consistent with this, AKT substrate, PRAS40 was also more highly phosphorylated (pT246) in such cells (Figure 1A, lower panel quantification). Furthermore, we observed that $M A P 3 K 1$ knock-down in T47D and MCF10A-PI3K $\alpha^{\mathrm{H} 1047 \mathrm{R}}$ made cells less sensitive to AZD8835-mediated pathway inhibition, as assessed by pPRAS40 signal (Figure 1A). These observations are all consistent with MAP3K1-PI3K pathway crosstalk.

To further investigate the effect of MAP3K1 depletion on PI3K $\alpha$ signaling, we generated MAP3K1deficient stable cells lines derived from MCF7 cells (harboring a PIK3CA E545K hotspot mutation) using precise genome editing CRISPR methodology Supplementary Figure 1B). Efficient depletion of MAP3K1 was confirmed by Sanger sequencing, NGS sequencing and western blotting (Supplementary Figure 1C-1E). We implemented bio-computational analysis to predict potential off-targets (description in materials and methods) to check the specificity of the guide RNAs in potential off-target loci, so as to select cells lines with modification specific to the MAP3K1 loci (Supplementary Figure 1F). Such validated MCF7 (CR1.4 and CR.2.5) cell lines were treated with $\mathrm{PI} 3 \mathrm{~K} \alpha / \delta$ inhibitor AZD8835 and AKT inhibitor (AKTi) AZD5363 and compared with parental MCF7 cells (Figure 1B and Supplementary Figure 2A). We observed that MAP3K1 deficiency led to reduced inhibition of the pathway by AZD8835 and AZD5363 with a more pronounced effect on AZD5363 activity, indicated by maintained pP70S6K, pPRAS40 and pS6 ribosomal protein (RP) readouts in CR1.4 and CR.2.5 compared with parent cells. To demonstrate that these effects were not restricted to AZD5363, we used a chemically different AKTi, GDC-0068 (ipatasertib) which was similarly impacted by MAP3K1 depletion (Supplementary Figure 2A). Proliferation assays revealed that MAP3K1-deficient cell lines exhibited a mean $\sim 2.4$-fold increased proliferation rate and decreased sensitivity to both AZD8835 and AZD5363 ( 2.61 and $\sim 5.23$-fold $\mathrm{IC}_{50}$ increases, respectively) compared with parental control cell lines (Supplementary Figure 2B). An example of a marked effect with AZD5363 is shown as a proliferation time course of CR2.5 cells compared to parental cells following treatment with either AZD8835 or AZD5363 (Figure 1C). Altogether these results indicated that MAP3K1 depletion in a $m P I K 3 C A$ background decreased sensitivity to AZD8835 and promoted resistance to AZD5363. This was consistent with the hyper-activation of the PI3K pathway, exemplified by enhanced AKT phosphorylation and downstream signaling of pPRAS40, pP70S6K and pS6 RP.

\section{MAP3K1 depletion elicits stability of IRS1, impacting on activation of PI3Ka and Ras/Raf/ Mek/Erk pathways}

It has been reported that MAP3K1 downstream target, JNK, mediates IRS1 degradation via phosphorylation [22-24, 30]. We first aimed to confirm the effective inhibition of the MAP3K1-JNK signaling pathway in CRISPR modified MAP3K1-deficient cell lines by measuring pJNK levels (Figure 2A). pJNK levels were lower in MAP3K1-deficient cells compared with control parental MCF7 cells under normal conditions. In addition, as anticipated since $\mathrm{JNK}$ is a downstream target of the MAP3K1 pathway, MAP3K1-deficient cells were unable to activate JNK following AZD8835 and AZD5363 treatments, in contrast to parental cells (Figure 2A and Supplementary Figure 2C). Furthermore, as previously reported [22, 24], reduced activation levels in JNK correlated with a lower level of serine 312 phosphorylation on IRS1 (pIRS1 (S312)) (Figure 2A and Supplementary Figure 2C). To test whether altered IRS1 phospho-status might impact IRS1 stability we performed cycloheximide (CHX) pulse-chase experiments to determine IRS1 protein half-life (Figure 2B). IRS1 protein levels decreased after 4-8h CHX treatment and were undetectable at the $16 \mathrm{~h}$ time point in parental control cells (Figure 2B). The kinetics in the MAP3K1 deficient cells changed significantly with stable IRS1 protein levels for at least 16h during CHX treatment. This observation was particularly remarkable in the MCF10A-PI3K $\alpha^{\mathrm{H} 1047 \mathrm{R}}$ model, with undetectable IRS1 protein levels at any time point in control parental cells versus highly stable levels at $16 \mathrm{~h}$ in the MAP3K1 deficient cells (Supplementary Figure 2D). In addition, we found that pIRS1 (S312), target of JNK [22, 23, 30] was differentially stimulated by AZD5363 in parental versus MAP3K1 deficient cell lines (Figure 2B and Supplementary Figure 2C). Hence we considered that the increase in IRS1 stability, associated with reduced pIRS1 (S312), could impact on overall IRS1 activity and PI3K $\alpha$ output, as previously reported [31]. Therefore, we next examined whether this alteration in IRS1 stability could impact assembly of the PI3K $\alpha$ complex [31] by 
immunoprecipitating proteins associated with the PI3K $\alpha$ regulatory subunit p85 $[32,33]$. We were able to immunoprecipitate IRS1 in DMSO treated MCF7 parental cells together with p85 but not after AZD5363 treatment (Figure 2C). In contrast, in MCF7 CR2.5 cells, IRS1 immunoprecipitated with p85 in both DMSO and AZD5363treated cells (Figure 2C). Altogether, this may suggest that deficiency in MAP3K1-JNK pathway signaling results in decreased pIRS1 (S312) levels, thereby promoting IRS stability and maintained IRS1/p85 interaction, which is directly associated with PI3K $\alpha$ activity. In particular, our findings suggest that at least part of the AZD5363 resistance mechanism in MAP3K1-deficient cells might be explained by resilient IRS1/p85 interaction. However, we were mindful that IRS1 facilitates the activation of at least two cell signaling pathways, PI3K $\alpha$ and Ras/Raf/ Mek/Erk [32, 34]. Also, despite partial PI3K pathway blockage following AZD5363 treatment (Figure 1B and Supplementary Figure 2A), MAP3K1-deficient cell lines seem able to sustain high proliferation rates (Figure 1C). Therefore, to further explore how MAP3K1 deficiency facilitates bypass of AZD5363-mediated PI3K pathway inhibition, we investigated whether ERK signaling might be additionally impacted by increased IRS1 activity, given a previous report that ERK $1 / 2$ can be stimulated, via Ras, following IRS1 activation [35]. We tested ERK1/2 activation levels in our model in basal conditions and following AZD5363 treatment (Figure 2D). We found
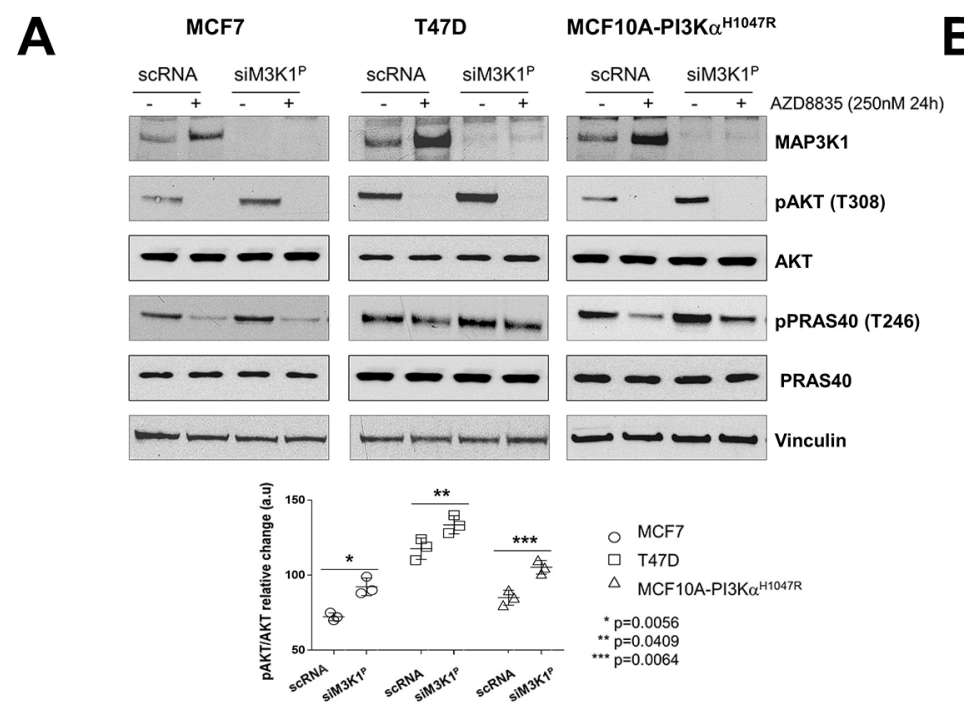

B

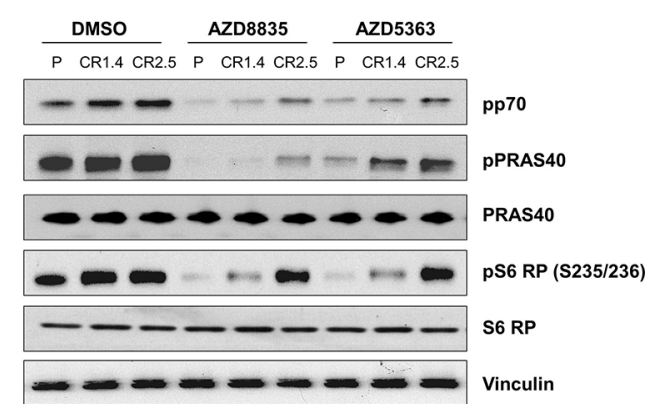

C

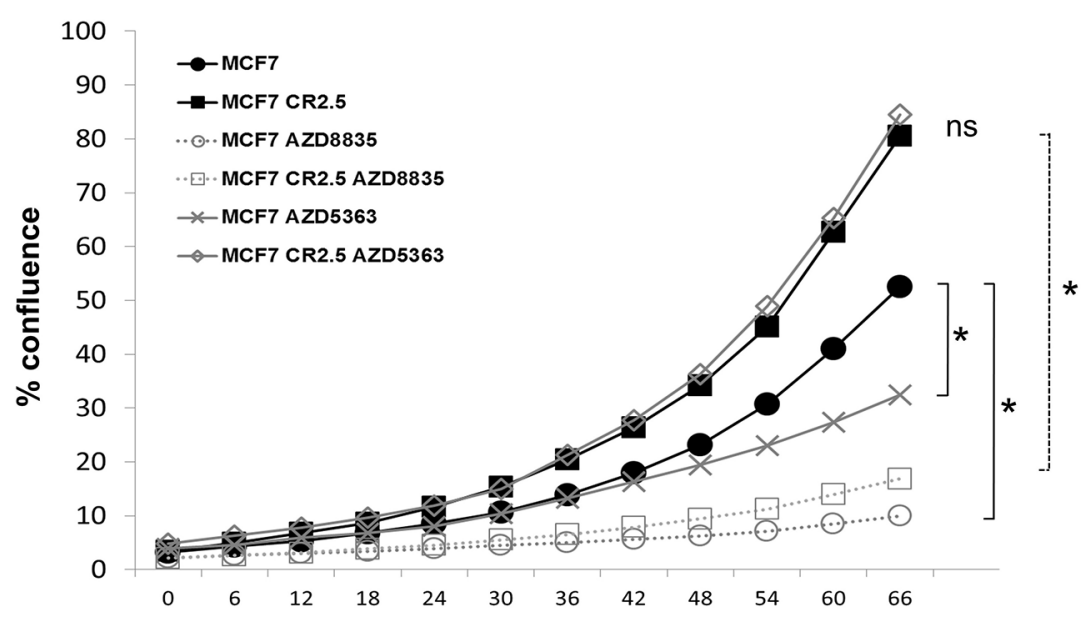

Figure 1: MAP3K1 inhibition reduces sensitivity to upstream PI3K pathway inhibitors. (A) MCF7, T47D and MCF10A$\mathrm{PI} 3 \mathrm{~K} \alpha^{\mathrm{H} 1047 \mathrm{R}}$ cells were cultured and transfected with $M A P 3 K 1$ (siM3K1 ${ }^{\mathrm{P}}$ ) or control (scRNA) siRNAs for $48 \mathrm{~h}$. Cultures were treated with 250nM AZD8835 (+) or DMSO (-) as indicated 24h prior to cell lysis. Cell lysates were then immunoblotted with indicated antibodies (Abs). P-values were determined by the Student's $t$-test. (B) Lysates from MCF7 parental and MAP3K1-deficient (CR1.4 and CR2.5) cells were cultured and treated with $250 \mathrm{nM}$ AZD8835 or $25 \mathrm{nM}$ AZD5363 as indicated. Lysates were collected and processed for immunoblotting with the indicated Abs. (C) IncuCyte cell proliferation assays showing relative \% of confluence of MCF7 parental versus MAP3K1-deficient (CR1.4 and CR2.5) cultures treated with DMSO (black), AZD8835 (red) and AZD5363 (green) for 66 hours. ${ }^{*}$ Statistical significance of $\mathrm{p}<0.05$, determined by the Student's $t$-test. 
that MAP3K1-deficient MCF7 cells had increased basal ERK1/2 activation level (phospho-ERK [pERK]) compared to parental MCF7 cells (Figure 2D). Further, AZD5363 treatment increased pERK levels in both control and MAP3K1-deficient cells, more prominently in the latter (Figure 2D), perhaps due to increased IRS1 stability. We therefore propose that ERK signaling acts as a possible escape route in MAP3K1-deficient cells, enabling bypass of AZD5363-mediated PI3K pathway blockage and sustaining cell proliferation.

\section{Organoid models reveal that MAP3K1 depletion promotes apoptosis resistance and increases proliferation}

In order to further characterize the effect of MAP3K1 depletion on proliferation and survival of $m P I K 3 C A$ BrCa cells, we performed 3D-matrigel in vitro growth assays which represent a more physiological approach than regular 2D in vitro cultures [36-38]. In matrigel our MCF10A cells underwent a series of morphogenic events consistent with the development of acinar structures with a hollow lumen [36, 37, 39-42]. Measuring volume of 3D-acinar structures cultured in matrigel for 15 days, we observed that MAP3K1deficient MCF10A-PI3K $\alpha^{\mathrm{H} 1047 \mathrm{R}}$ acini (CR2.9) appeared larger compared with control MCF10A-PI3K $\alpha^{\mathrm{H} 1047 \mathrm{R}}$ acini and their growth was significantly less inhibited by AZD5363 (Figure 3A). To determine the cause of increased acinus size in MAP3K1-deficient cultures we immuno-stained acini with apoptosis (cleaved caspase 3, $\mathrm{c}-\mathrm{c} 3$ ) (Figure 3B, upper panels) and the proliferation $(\mathrm{pRb})$ (Figure 3B, lower panels) markers. Luminal occlusion is a hallmark of early stages of breast tumorigenesis such as ductal carcinoma in situ [38, 43]. It has been shown that MCF10A acini stably expressing PI3K $\alpha^{\mathrm{H} 1047 \mathrm{R}}$ exhibit luminal filling [44]. Accordingly, we observed this in images from equatorial sections of control DMSOtreated MCF10A-PI3K $\alpha^{\mathrm{H} 1047 \mathrm{R}}$ and MCF10A-PI3K $\alpha^{\mathrm{H} 1047 \mathrm{R}}$ MAP3K1-deficient (CR2.9) acini (Figure 3B). Apoptotic cells were primarily found in the lumen compartment and the number of events ( $2 \mathrm{c}-\mathrm{c} 3+$ /acinus $)$ was similar both in control and CR2.9 acini (Figure 3B, graph i). As expected AZD5363 treatment increased significantly the number of apoptotic events ( $12 \mathrm{c}-\mathrm{c} 3+$ /acinus $)$ in control MCF10A$\mathrm{PI} 3 \mathrm{~K} \alpha^{\mathrm{H} 1047 \mathrm{R}}$ acini. However, AZD5363 treatment did not increase significantly the number of apoptotic events $(\sim 5$ c-c3+/acinus) in MAP3K1-deficient acini (Figure 3B, graph i). Next, proliferative cells were stained for $\mathrm{pRb}$ in control DMSO-treated MCF10A-PI3K $\alpha^{\mathrm{H1047R}}$ and CR2.9 acini (Figure 3B, lower panels). In control conditions CR2.9 acini exhibited increased number of $\mathrm{pRb}$ positive cells ( $\sim 8 \mathrm{pRb}+$ /acinus) compared with parental MCF10A$\mathrm{PI} 3 \mathrm{~K} \alpha^{\mathrm{H} 1047 \mathrm{R}}$ acini ( $\sim 6 \mathrm{pRb}+$ /acinus). Strikingly, whereas AZD5363 administration dramatically reduced the number of proliferative cells in parental MCF10A-PI3K $\alpha^{\mathrm{H} 1047 \mathrm{R}}$ acini, it did not significantly reduce the number of $\mathrm{pRb}+$ events in CR2.9 acini (Figure 3B, lower panels and graph ii). This suggests that MAP3K1 depletion enhances proliferation and promotes resistance to AZD5363mediated induction of apoptosis and AZD5363-mediated inhibition of proliferation.

Next, we sought to understand whether the highly proliferative and low apoptotic phenotype observed in MAP3K1-deficient acini was accompanied by hyperactivation of the PI3K pathway and/or insensitivity to AZD5363 treatment. Previous 2D in vitro experiments had revealed that MAP3K1-deficient cell lines (MCF7 and MCF10A-PI3K $\alpha^{\mathrm{H} 1047 \mathrm{R}}$ models) were resistant to AZD5363-mediated pS6 RP inhibition (e.g. Figure 1B). To test whether this effect prevailed also in $3 \mathrm{D}$-acini we immuno-stained for pS6 RP in MCF10A-PI3K $\alpha^{\mathrm{H} 1047 \mathrm{R}}$ acini (Figure 3C). Confocal equatorial sections revealed comparable levels of pS6 RP signal in both control and MAP3K1-deficient acini when treated with DMSO. Matrigel substrate enables integrin and receptor tyrosine kinase coupling which transduces proliferative signaling in the basal compartment $[45,46]$. Consistent with this, we observed increased pS6 RP intensity in the basal compartment of outer rim cells (Figure 3C, detailed images). AZD5363 reduced substantially pS6 RP signal in control MCF10A-PI3K $\alpha^{\mathrm{H} 1047 \mathrm{R}}$ acini when compared with DMSO-treated acini. In contrast, pS6 RP levels remained considerably higher both in DMSO and AZD5363-treated CR2.9 acini, consistent with our previous 2D observations (Figure 1B) that MAP3K1 depletion results in AZD5363 resistance.

\section{MAP3K1-deficient tumors are relatively resistant to AZD5363 treatment}

Our evidence from 2D and 3D in vitro studies supported the notion that MAP3K1 depletion elicited elevated proliferation rates and reduced sensitivity to AKT inhibition. We then sought to confirm our observations in vivo using a xenograft model. We implanted MCF7 parental and CR2.5 cell lines in mice and treated with $150 \mathrm{mg} / \mathrm{kg}$ BID AZD5363 for 28 days. We measured tumor volumes and observed that AZD5363 treatment significantly reduced (22\%) mean tumor volume (MTV) of MCF7 parental tumors whereas it had no effect on MCF7 CR2.5 tumors, at day 18 of treatment (Figure 4A). Notably, we quantified a significant MTV reduction (27\%) in MCF7 parental versus a non-significant MTV reduction (18\%) in MCF7 CR2.5 tumors at day 28 of treatment (Supplementary Figure 3A). These data indicate that MCF7 CR2.5 xenografts exhibit reduced sensitivity to the AKTi, suggesting that MAP3K1 deficiency promotes resistance to AZD5363 in vivo.

Surprisingly, we observed that prior to dosing (day 18 post-implantation) MTV of MCF7 CR2.5 tumors was significantly smaller than parental tumors (Supplementary 
Figure 3B, left panel). Evidence in the literature indicates that an activated MAP3K1-JNK axis correlates with enhanced cell growth and size $[47,48]$ and we observed that regardless of background (cell area quantification of bright field images from MCF7, and MCF10A-PI3K $\alpha^{\mathrm{H} 1047 \mathrm{R}}$ or T47D in vitro cultures [not shown]) MAP3K1deficient cells appeared smaller than parental. Thus we hypothesized that the smaller size of CR2.5 tumors versus parental tumors could be attributable to the smaller size of CR2.5 mutant cells. To investigate this, we performed cell number count and cell area estimation using HALO software (Supplementary Figure 3B, middle and right panels). We demonstrated that CR2.5 tumors exhibited increased number of cells per area. Further, the size of these cells was significantly smaller than in parental MCF7 tumors.

To mechanistically characterize the function of MAP3K1 in this AZD5363-resistant phenotype we first

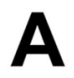

C

IP: p85
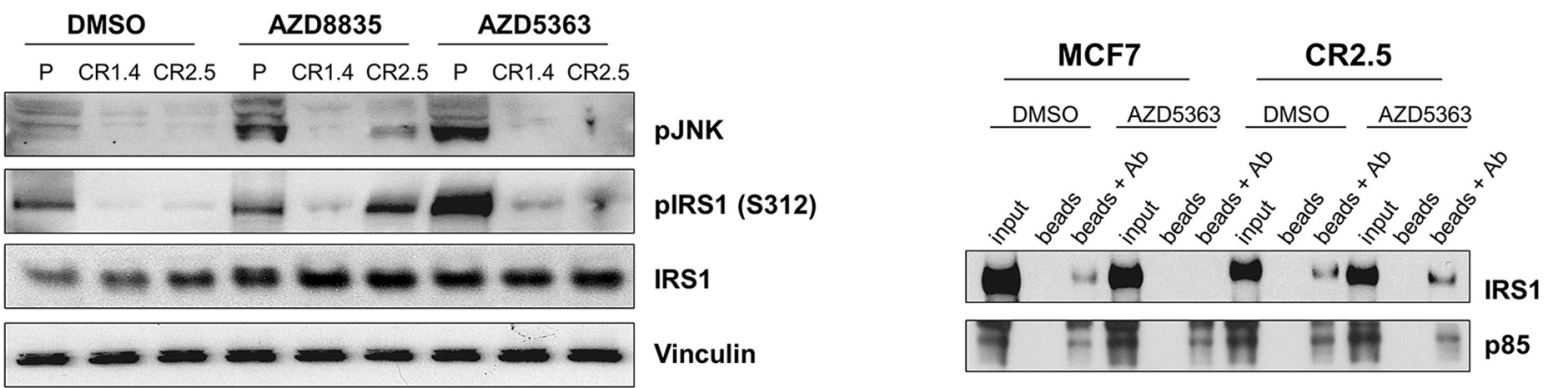

B

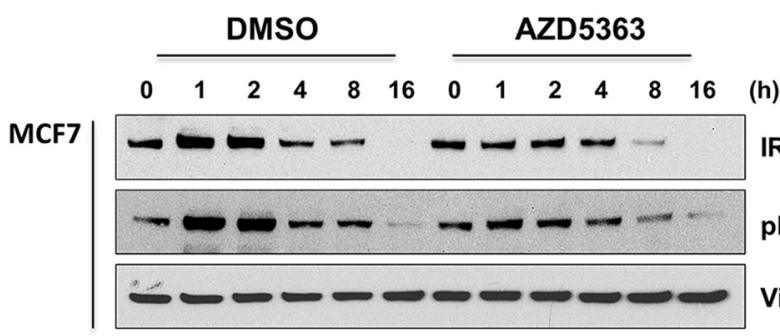

(h) $\mathrm{CHX}$

D

IRS1

pIRS1 (S312)

Vinculin

$\begin{array}{llllllllllll}0 & 1 & 2 & 4 & 8 & 16 & 0 & 1 & 2 & 4 & 8 & 16\end{array}$

(h) $\mathrm{CHX}$

CR1.4

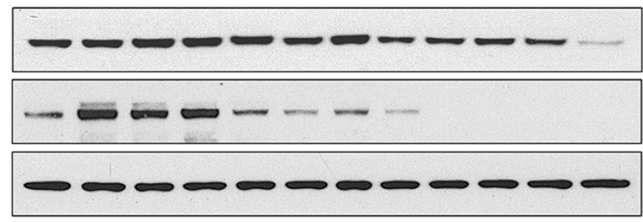

IRS1

pIRS1 (S312)

Vinculin
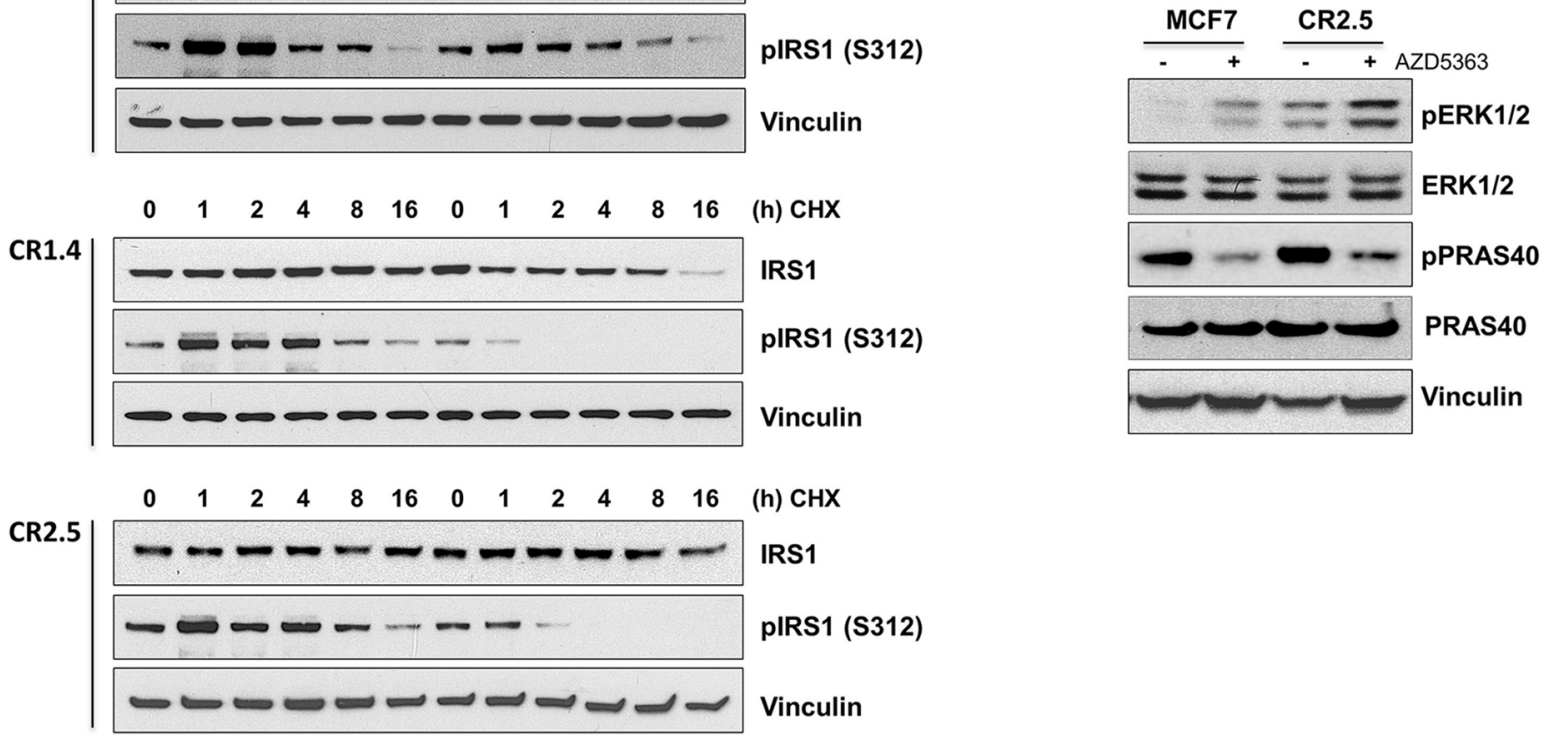

(h) $\mathrm{CHX}$

IRS1

pIRS1 (S312)

Vinculin

Figure 2: MAP3K1 depletion correlates with increased IRS1 stability. (A) MCF7 parental, CR1.4 and CR2.5 cells were treated with $250 \mathrm{nM}$ AZD8835, $250 \mathrm{nM}$ AZD5363 or DMSO 24h prior to cell lysis. Cell lysates were collected and immunoblotted with indicated Abs. (B) MCF7 parental, CR1.4 and CR2.5 cells were incubated with $50 \mu \mathrm{g} / \mathrm{ml}$ cycloheximide (CHX) at the indicated time points in the presence or absence of AZD5363 and immunoblotted with total- and phospho (Ser312)-IRS1 specific Abs. Densitometry quantification is shown in Supplementary Figure 2D. (C) Whole cell lysates were incubated with PI3K regulatory subunit (p85) Abs overnight. Immunocomplex pull-downs were performed using magnetic Protein A beads and immunoblotted with the indicated Abs. (D) Immunoblots from MCF7 parental and CR2.5 cells cultured in the presence (+) or absence (-) of AZD5363 and immunoblotted with the indicated Abs. 
A

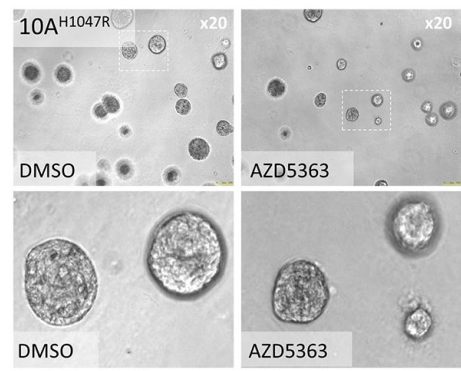

B
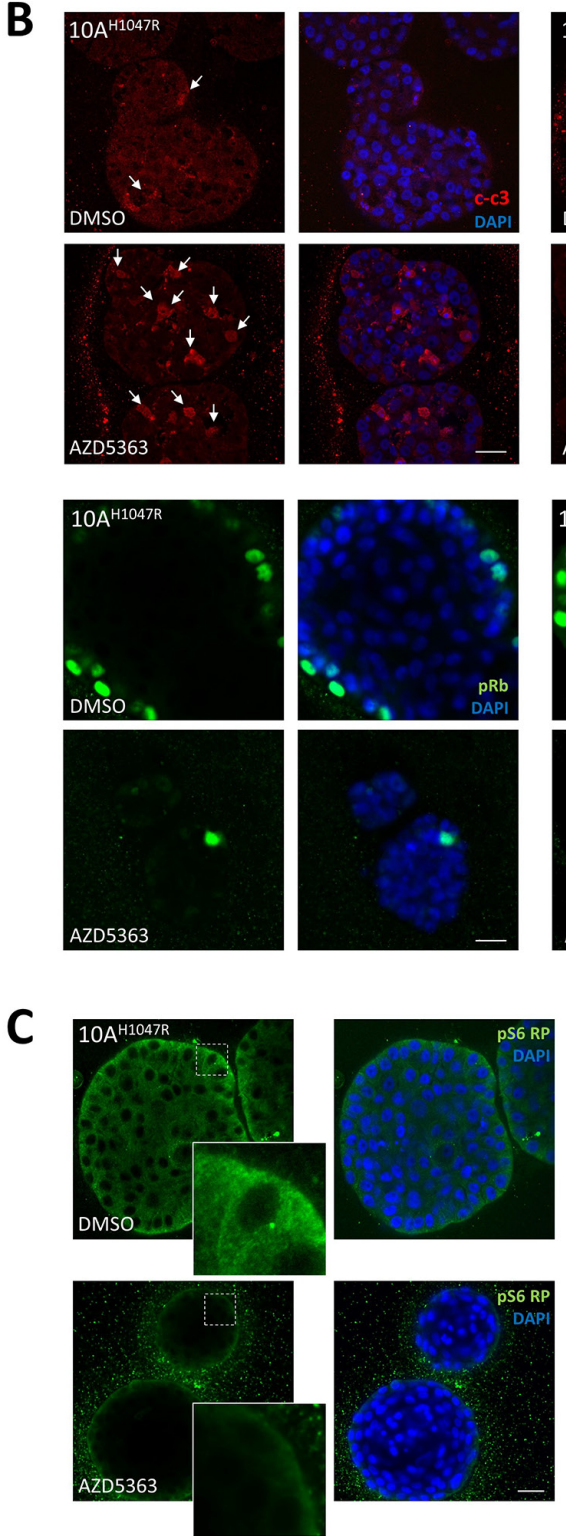
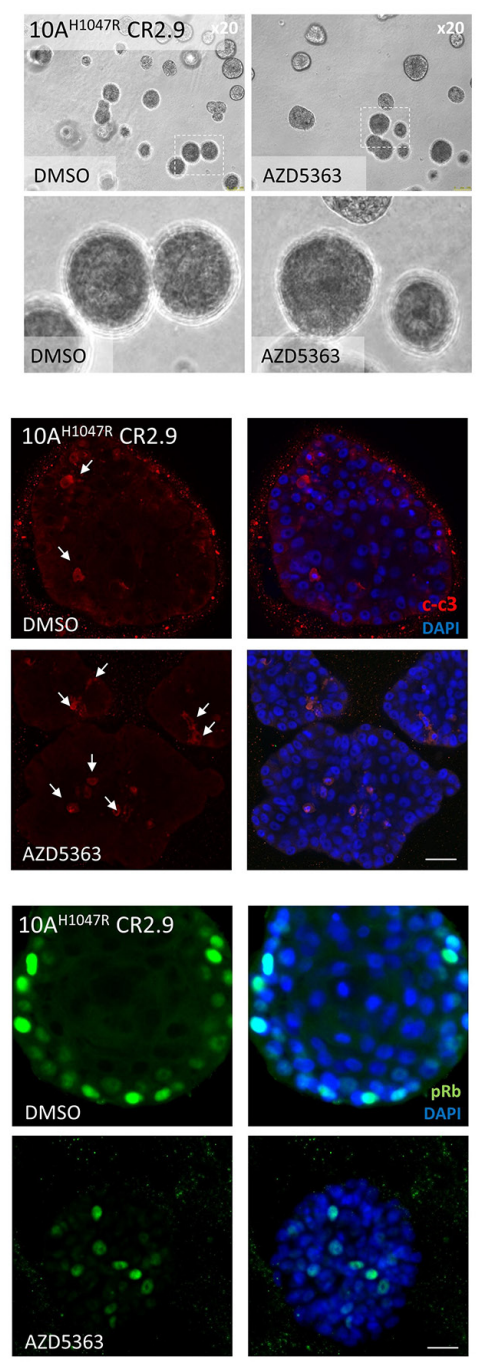

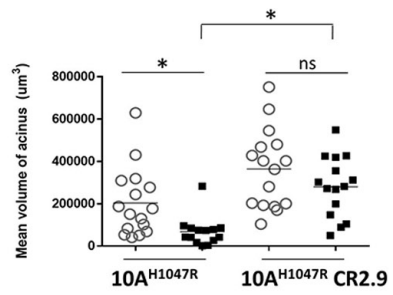

DMSO

- AZD5363 $(2 \mu \mathrm{M})$

i)

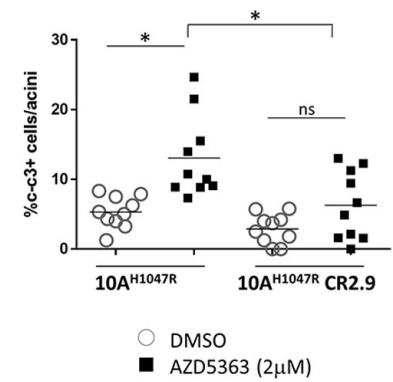

ii)

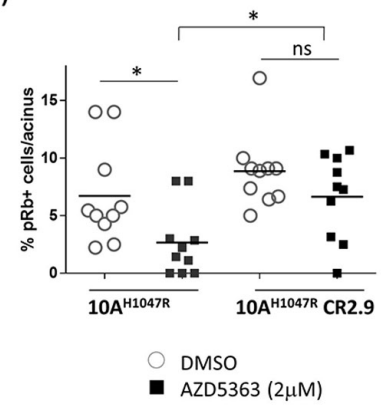

Figure 3: MAP3K1 depletion in 3D-MCF10A-PI3K $\alpha^{\mathrm{H} 1047 \mathrm{R}}$ acini elicits apoptosis resistance and increased proliferation. (A) Representative bright field images from parental and MAP3K1-deficient MCF10A-PI3Ka ${ }^{\text {H1047R }}$ acini atday 15 of morphogenesis. Acini were treated from day 4 to day 15 with $10 \mu \mathrm{M}$ AZD5363 as indicated. Right graph represents mean volume of acini which was calculated using SPOT software following the equation $\left[\left(\right.\right.$ length $\times$ width $\left.^{2}\right) / 2=$ acinus volume $\left.\left(\mathrm{mm}^{3}\right)\right](\mathrm{N}=10)$. (B) Confocal equatorial images from parental and MAP3K1-deficient MCF10A-PI3Ka ${ }^{\text {H1047R }}$ treated from day 4 to day 15 with 10mM AZD5363. At day 15 of morphogenesis acini were fixed and immunostained using cleaved caspase 3 (c-c3) (upper panels) and $\mathrm{pRb}$ (lower panels) Abs. Quantification of events is represented on right graphs $(\mathrm{N}=20)$. (C) In identical conditions as in (b) acini were stained using pS6 RP Abs. Right graph shows the mean intensity in arbitrary units (a.u) of pS6 RP signal calculated with ImageJ $(\mathrm{N}=20)$. Scale bars indicate $25 \mu \mathrm{m}$. P-values were determined by the Student's $t$-test. 
sought to understand whether MAP3K1 depletion was impacting PI3K pathway signaling. On vehicle treatment, we observed a non-significant trend toward increased pS6 RP activity in MCF7 CR2.5 versus parental tumors (Figure 4B and Supplementary Figure 4A, left panels). In addition, while AZD5363 administration efficiently reduced pS6 RP activity in parental tumors, it had no effect on pS6 RP activity levels in CR2.5 tumors. This was in agreement with our previous in vitro studies (Figure 1B and 3C), indicating that MAP3K1-depletion correlates with increased PI3K pathway signaling and AZD5363 resistance. Next, we sought to understand whether MAP3K1-depletion has a functional effect on IRS1 activity in vivo. We immune-stained parental and CR2.5 tumors sections for pIRS1 (Ser312). We did not observe any effect either in parental and CR2.5 tumors in vehicle-treated conditions (Figure 4B and Supplementary Figure 4A, right panels). However, a significantly greater reduction in pIRS1 activation levels was observed on AZD5363 treatment when comparing MAP3K1-deficient versus parental tumors. Again this result agreed with previous in vitro observations (Figure $2 \mathrm{~A}$ and $2 \mathrm{~B}$ ). To test whether the pS6 RP and pIRS1 phenotype of MAP3K1deficient xenograft had an impact on proliferation we measured $\mathrm{pRb}$ in situ by using immunostaining (Figure 4C). We observed a significant reduction in the number of $\mathrm{pRb}+$ events in parental MCF7 tumors following AZD5363 treatment whereas this effect was not observed in MCF7 CR2.5 tumors (Figure 4C and Supplementary Figure 4B). This result suggests that in the context of xenograft tumor growth, MAP3K1 depletion counteracts the anti-proliferative effect of AZD5363 in tumor growth.

To summarize, genetic inactivation of $M A P 3 K 1$ in the context of $m P I K 3 C A$ resulted in reduced sensitivity to the AKTi AZD5363. Importantly, upon AZD5363 treatment, MAP3K1-deficient tumors exhibited increased proliferation rate and were $\mathrm{pS} 6 \mathrm{RP}^{\mathrm{HIGH}}$ and $\mathrm{pIRS} 1^{\mathrm{LOW}}$ when compared with parental controls, in agreement with our cell culture and organoids results.

\section{DISCUSSION}

Here we identify a previously unrecognized crosstalk between the PI3K $\alpha$ and MAP3K1/JNK pathway and demonstrate its potential impact in cancer therapy resistance. Specifically, we demonstrate that depletion of $M A P 3 K 1$ gene expression in the context of $m P I K 3 C A$ $\mathrm{BrCa}$ cell lines causes resistance to $\mathrm{PI} 3 \mathrm{~K}$ pathway inhibition by PI3K pathway inhibitors, manifested as resistance to proliferation inhibition in vitro. Our results indicate that depleted MAP3K1/JNK signaling correlates with decreased pIRS1, enhanced IRS1 half-life and persistent binding to the PI3K regulatory subunit, $\mathrm{p} 85$. Moreover, in vivo studies demonstrate that MAP3K1 deficiency in MCF7 xenografts elicits relative AKTi inhibitor resistance. Immuno-histological analysis revealed that MAP3K1-deficient tumors are $\mathrm{pRB}^{\mathrm{HIGH}}$ and $\mathrm{c}-\mathrm{c} 3^{\text {LOW }}$ suggesting a higher proliferation rate. Strikingly, these tumors are also pS6 $\mathrm{RP}^{\mathrm{HIGH}}$, in agreement with our in vitro and 3D-organoid evidence showing reduced AZD5363 mediated inhibition of the PI3K pathway in a MAP3K1-deficient background. Specifically, our work provides important insights into how the mutational status of PIK3CA and MAP3K1 genes could predict response to AZD5363 and other PI3K pathway inhibitors.

Given the PI3K pathway is frequently deregulated in cancer, our study raises important questions on how patient stratification based on mutational status of key components of this and other pathways might be critical in order to achieve optimal clinical anti-tumor efficacy. Due to the relatively disappointing outcomes of clinical trials targeting $m P I K 3 C A$ tumors with $\mathrm{PI} 3 \mathrm{~K} \alpha$ inhibitors, a number of studies are currently under investigation targeting other PI3K pathway mediators [49]. We sought to evaluate the efficacy of the AKTi AZD5363, a distal PI3K pathway inhibitor, and interrogated its efficacy in different mutational scenarios. Our results suggest that tumors with concomitant $P I K 3 C A$ gain of function mutation and $M A P 3 K 1 \mathrm{LoF}$ mutation are less responsive to AKTi treatment, at least in monotherapy. Our initial studies with the PI3K $\alpha / \delta$ inhibitor, AZD8835, pointed to similar findings.

One of the aims of this work was to characterize cross-talk between the PI3K $\alpha$ and the MAP3K1 pathways, specifically, how this impacts on resistance to PI3K pathway inhibitors. With the exception of the study by Park H.S. et al which describes the direct phosphorylation of MAP2K4 by AKT [21], there is no evidence in the literature of a direct cross-talk between PI3K $\alpha$ and the MAP3K1 pathways. Our study delineates first clearly identified cross-talk between MAP3K1-JNK and PI3K pathways, with IRS1 being a key nodal point connecting the pathways. Phospho-status of IRS1 determines its stability and subsequent $\mathrm{PI} 3 \mathrm{~K} \alpha$ kinase activity [50]. Further, post-translational modifications dictate its conformational structure that ultimately determine its affinity for the PI3K $\alpha$ subunit, p85 [51, 52]. Stabilization of IRS1 in the PI3K $\alpha$ complex correlates with signaling and this appears critical in explaining the resistance mechanism to AZD5363.

We observed that AZD5363 and AZD8835 treatment increases MAP3K1 expression (Supplementary Figure $1 \mathrm{E})$; this increase correlates with enhanced phosphoJNK activity (Figure 2A) suggesting full activation of the pathway. We have not investigated the mechanisms underlying this increase in $\mathrm{pJNK}$ but we believe this could be anticipated since MAP3K1 is a recognized sensor of external insults and it is reasonable that MAP3K1 could be induced following administration of therapeutic agents [12]. This mechanism might have positive anti-tumor effects, since MAP3K1 induction following AZD5363 and AZD8835 administration would elicit (via JNK) IRS1 
Ser312 phosphorylation and IRS1 degradation and thereby oppose counteracting signals in response to PI3K pathway inhibition such as from the $\mathrm{p} 70^{\mathrm{S} 6 \mathrm{~K}}$ feed-back loop [25].

In the present study, MAP3K1-deficient cells exhibit a significant increase of PI3K pathway activation levels when compared with parental cells, even in the presence of AZD5363. Activation of AKT and downstream targets leads to inhibition of apoptosis, cell survival and correlates with tumor progression [53]. Although this may in part explain the AZD5363-resistant phenotype of MAP3K1deficient tumors, we suspected that other pathways may be involved in bypass of AKT blockage. Since IRS1 also mediates Ras activation, one obvious candidate was the Ras/Raf/Mek/Erk pathway [54, 55]. In our hands,

A
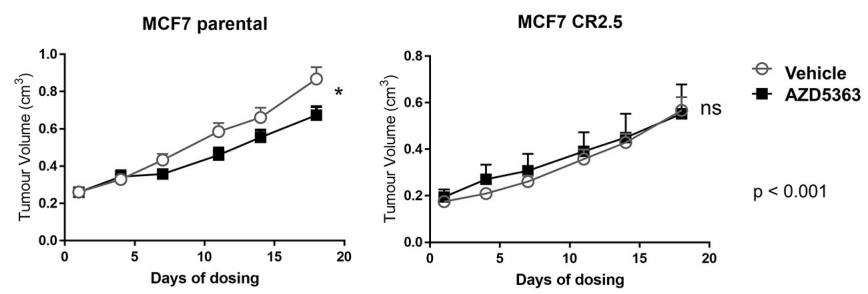

B
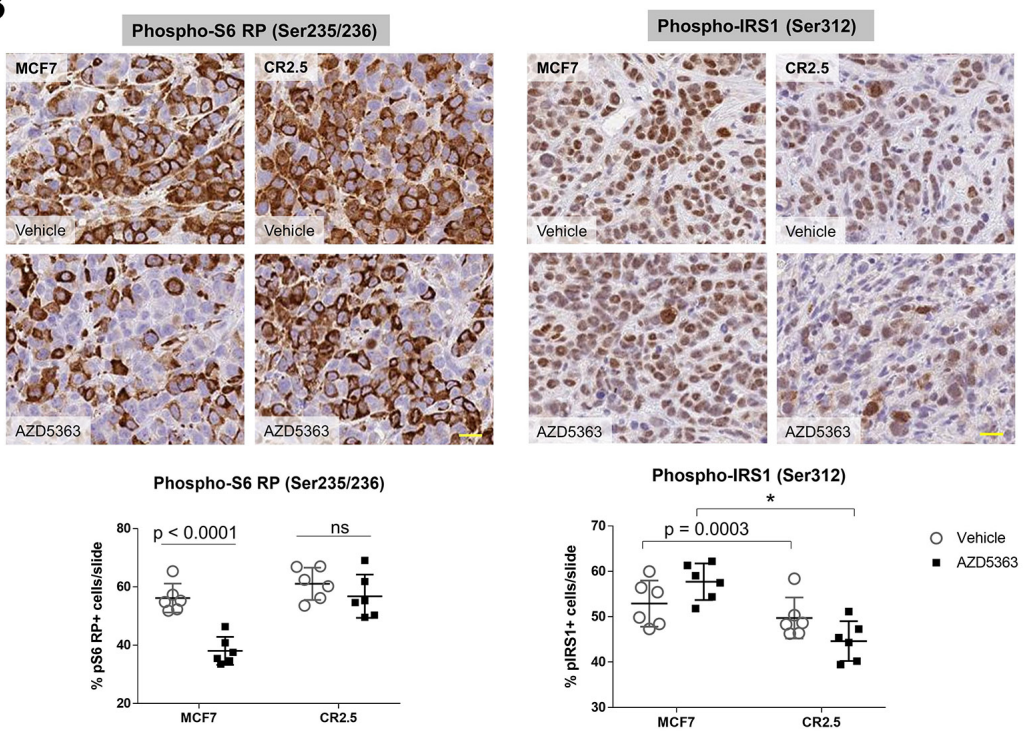

C
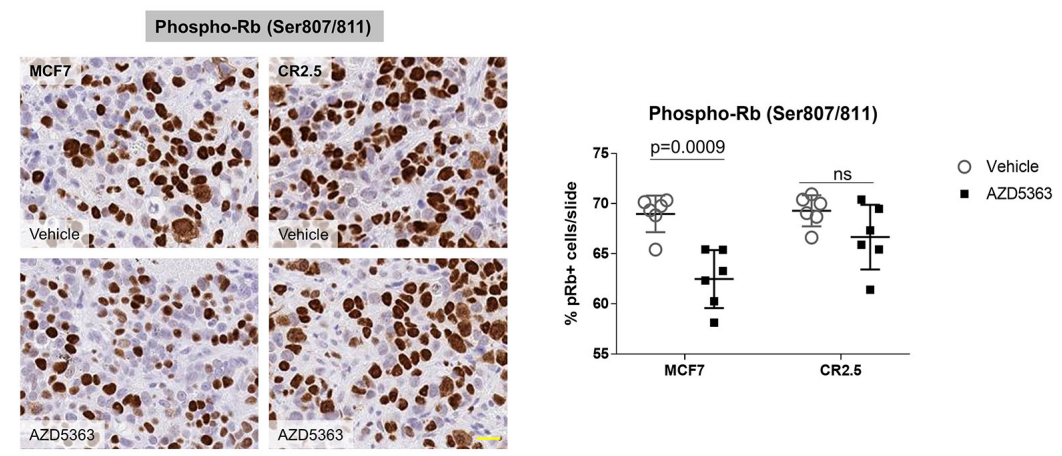

Figure 4: MAP3K1-deficient tumors are resistant to AZD5363 treatment. (A) Quantification of tumor volume following vehicle or AZD5363 treatment in MCF7 parental (upper left panel) versus MCF7 CR2.5 (upper right panel) xenograft after 18 days dosing. P-values were determined by the Student's $t$-test. (B and C) Representative immunostainings of phospho-S6 RP, phospho-IRS1 (B) and phospho-Rb (C) markers in MCF7 parental and MCF7 CR2.5 xenografts sections from xenograft tumors. Scale bars (yellow) represent 20 $\mu \mathrm{m}$. Graphs show analysis and quantification of positive events using HALO (indica labs). The resulting algorithm was applied to the whole slide $(n=6)$ (see Supplementary Figure 4 for more details). P-values were determined by the Student's $t$-test. 
AZD5363 administration correlates with high pERK levels and this is further enhanced when MAP3K1 is depleted (Figure 2D and Figure 5, right scheme). We also propose that increased IRS1 stability as a consequence of MAP3K1-depletion results in enhanced Ras/Raf/Mek/ Erk signaling. We propose that drugs targeting PI3K $\alpha$ signaling are sub-optimally effective because their effects are dampened by activation of parallel pathways such as Ras/Raf/Mek/Erk. On the contrary, co-administration of AKT with MEK inhibitors [56] can attenuate the negative feedback, restore AKTi sensitivity and may ultimately provide therapeutic benefit for patients with concomitant PIK3CA/MAP3K1 mutations.

Although some previous investigations clearly point toward a tumor suppressor role of MAP3K1 in the context of $m P I K 3 C A$, overall bibliographic evidence is not conclusive [4,6-11]. Tumor micro-environment is populated with a repertoire of different cellular subtypes that are implicated in numerous cellular responses (i.e. angiogenesis, immune response and metabolism) that ultimately impact on tumor fate and development [57, 58]. Therefore to further characterize the phenotypic impact of MAP3K1 depletion in tumor fate we implanted parental and MAP3K1-deficient MCF7 cells in nude mice and followed their growth for 28 days. Significant differences were observed when tumors were challenged with AZD5363; MAP3K1-deficient tumors were less sensitive to AZD5363, displaying higher proliferation rates compared with parental counterparts. Importantly, whereas AZD5363 efficiently reduced pS6 RP levels in parental tumors, these levels remained unchanged in MAP3K1-deficient ones, consistent with resistance to AKT inhibition.

We have observed that MAP3K1 is induced in the presence of PI3K pathway inhibitors such as AZD5363 or AZD8835 (Supplementary Figure 1E), in agreement with MAP3K1's role as transducer of external stress insults. We hypothesize that in the $\mathrm{mPIK} 3 C A$ context,

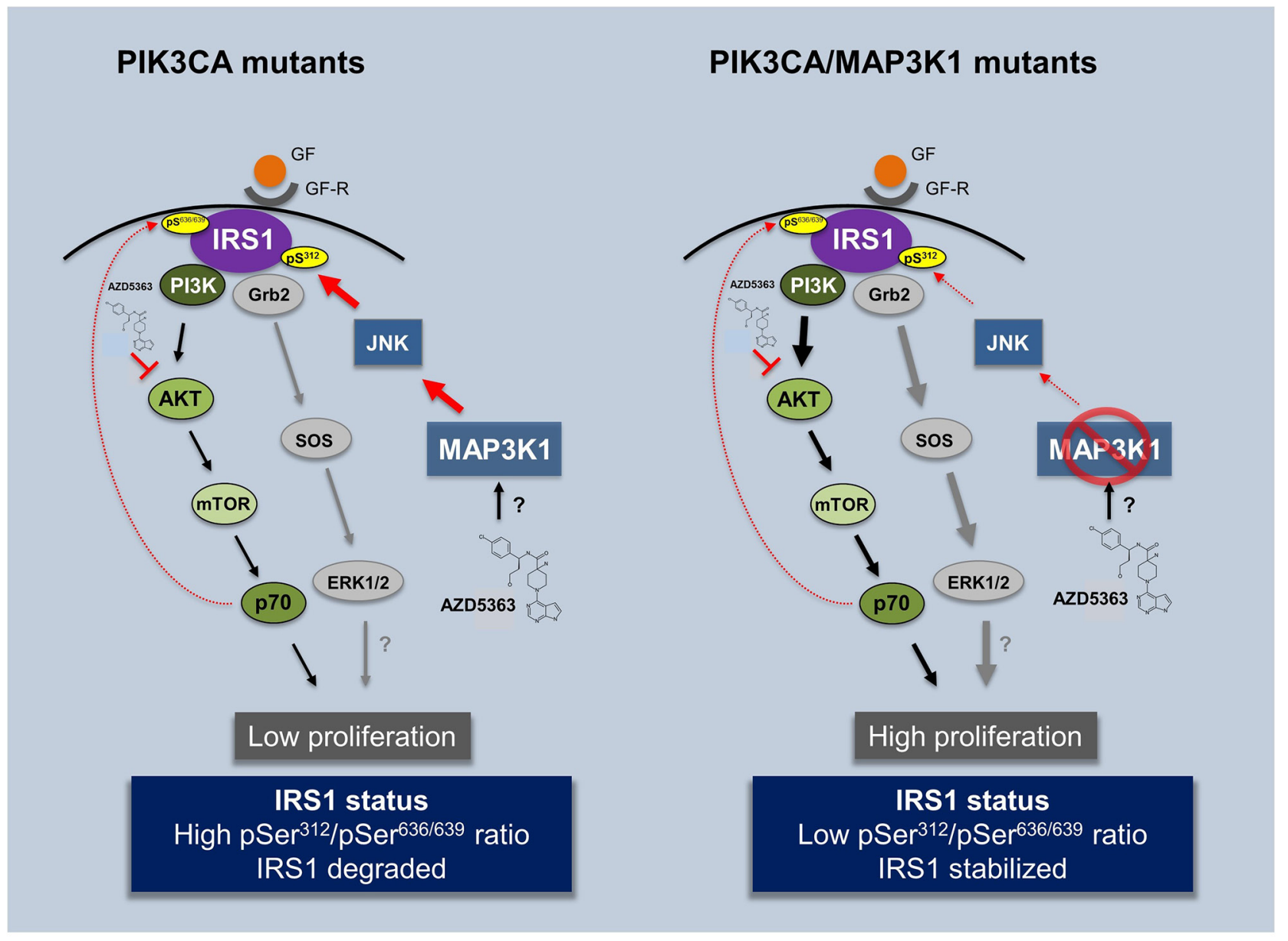

Figure 5: Impact of AZD5363 treatment in $P I K 3 C A$ and double mutant $P I K 3 C A / M A P 3 K 1$ patients. Illustration contemplating experimental (in vitro, 3D organoids and in vivo) and clinical observations presented in the study. AZD5363 can be used as an efficient compound to treat $m P I K 3 C A$ tumors by blocking the pathway at the level of AKT. However its efficiency may be compromised in patients harboring co-occurring $M A P 3 K 1$ LoF mutation. Patients with reduced MAP3K1 expression have deregulated JNK pathway activity and consequently decreased phospho-serine IRS1 (S312) levels. This increases IRS1 stability and subsequently brings about the re-activation of PI3K $\alpha . \mathrm{pS}$, phospho-serine, GF, growth factor, GF-R, growth factor receptor. 
AZD5363 exposure triggers enhanced MAP3K1 levels and high pIRS1 (Ser312) activity. This negatively impacts IRS1 stability resulting in reduced recruitment of the PI3K $\alpha$ regulatory subunit (p85) and reduced PI3K pathway signaling (Figure 5, left scheme). Thus, in this scenario AZD5363 has two additive anti-proliferative effects, firstly by blocking AKT directly and secondly via stimulating MAP3K1 which provides negative feed-back signaling through the IRS1-PI3K $\alpha$ axis. By contrast in the PIK3CA/MAP3K1 dual mutation scenario AZD5363 is less effective (Figure 5, right scheme), due to hyperactivation of the PI3K pathway via IRS1; furthermore, the loss of MAP3K1-JNK signaling allows for PI3K pathway bypass through deregulation of additional oncogenic pathways, for example Ras/Raf/Mek/Erk pathway [32, 34]. Preliminary observations indicate that ERK activity is enhanced in the MAP3K1-deficient context and is further enhanced in the presence of AZD5363. Although more insights need to be accrued, we propose the Ras/Raf/Mek/ Erk pathway is a potential route by which AKT inhibition can be bypassed.

In conclusion, our investigations indicate that $M A P 3 K 1$ LoF mutations, in the context of a $M P I K 3 C A$ background, may be considered as predictive biomarkers to evaluate efficacy of PI3K pathway inhibitors.

\section{MATERIALS AND METHODS}

\section{In vivo studies}

MCF7 parental and MAP3K1 deficient (CR2.5) cell lines were implanted subcutaneously in the flank of male SCID mice with estrogen pellet $(0.5 \mathrm{mg} / 21$ days $)$. Cells were implanted at a concentration of $5 \times 10^{6}$ cells/mouse with Matrigel at a total volume of $0.1 \mathrm{~mL}$. When tumors reached approximately $0.2 \mathrm{~cm}^{3}$ they were randomized into two groups, vehicle (10\% DMSO, 25\% Kleptose) and AZD5363 treatment (150 mg/kg) BID (twice daily), for 28 days. Mice were treated 32 times following a schedule (4 days on, 3 days off for 3 cycles and on the 4 th cycle tumors were dosed 4 days on) and subsequently sampled. Two hours post morning dose on the day of the last compound administration, tumors were excised and collected for analysis. All procedures were carried out in accordance with UK home office regulations and with approved institutional guidelines.

\section{Cell lines and treatments}

Low-passage MCF10A-PI3K $\alpha^{\mathrm{H1047R}}$ (from Horizon Discovery, Cambridge, UK) cells were cultured in the same conditions as parental MCF10A cells as described previously [40, 42]. MCF7 cells where cultured in phenol-free RPMI medium reconstituted with 10\% fetal calf serum. For AZD5363, AZD8835 and cycloheximide experiments cells were plated a day prior to treatment and drugs added in fresh medium at the indicated times and concentrations. For 3D cultures, cells were plated in growth factor reduced (GFR) BD Matrigel basement membrane matrix, phenol red free (BD Biosciences, San Diego, CA, USA) and grown as described [38]. For the proliferation assays cells were plated in 96-well plates at a 2000 cell/well density and confluence was measured with IncuCyte technology (Essen Bioscience, Ann Arbor, MI, USA).

\section{Western blots}

MCF10A and MCF7 cells were lysed in AZ cell panel lysis buffer supplemented with protease inhibitor cocktail (Roche, Welwyn Garden City, UK) and phosphatase inhibitor (Thermo Fisher Scientific, MA, US). Protein concentration was quantified with Pierce ${ }^{\mathrm{TM}}$ BCA Protein Assay Kit (Thermo Fisher Scientific) and equal amounts of protein were loaded and separated in Mini-PROTEAN® precast gels (Bio-Rad, CA, US). Membranes were transferred with iBlot ${ }^{\circledR} 2$ Transfer Stacks (Thermo Fisher Scientific, MA, US) and blotted against the following antibodies: phospho-SAPK/JNK (Thr183/ Tyr185), phospho-Rb (Ser807/811), phospho-S6 RP (Ser253/225), phospho-AKT (Thr308), phospho-PRAS40 (Thr246), cleaved caspase-3 (Asp175), phospho-ERK1/2 MAPK (Thr202/Tyr204), AKT, IRS1, phospho-IRS1 (Ser312), phospho-p70 S6 kinase (Thr421/Ser424), all purchased from Cell Signaling Technology (CST, MA, US); MAP3K1 (Santa Cruz Biotechnology, TX, US) and Vinculin (Sigma-Aldrich, MO, US). Anti-mouse or anti-mouse IgG horseradish peroxidase-linked secondary antibodies (CST) and Supersignal (Thermo Fisher Scientific) were used to detect bound antibodies.

\section{Immuno-precipitation}

Cell lysates were quantified and equal amounts were subject to immunoprecipitation overnight with PI3 Kinase p85 antibody (CST) or IgG mouse (CST) isotype control and Dynabeads Protein G (Invitrogen). Immunocomplexes where washed thrice with AZ cell lysis panel buffer and resuspended in pure water and NuPAGE LDS sample buffer and sample reducing agent (Thermo Fisher Scientific).

\section{CRISPR gene editing}

\section{Selection of target sites}

Two CRISPR target sites ( $\mathrm{Cr} 1$ : 5'-CAAGATGGATGATCGTCCAG-3' and Cr2: 5'-AGCCTGGAAGCACGAATGGT-3') against the second exon of the human $M A P 3 K 1$ gene were selected using MIT's CRISPR design tool (http://crispr.mit.edu/). Guide-RNAs (gRNAs) expression plasmids were constructed by ligating oligonucleotide duplexes into an 
AarI-linearized plasmid containing human U6 promoter and an optimized coding sequence of wild-type SpCas9 (Streptococcus pyogenes Cas9) under the control of CMV promoter. The sequence of the recombinant plasmids was confirmed using Sanger sequencing.

\section{Surveyor assay}

The mutant clones at MAP3K1 target sites were identified using Surveyor assay. Briefly, on- and off-target sites were amplified from $50 \mathrm{ng}$ of genomic DNA using Fusion-Flash HiFi DNA polymerase (Life Technologies) and primers (Supplementary Table 1). $10 \mu \mathrm{l}$ of PCR products were denatured and reannealed using a thermocycler with the following protocol: $95^{\circ} \mathrm{C}, 10 \mathrm{~min} ; 85^{\circ} \mathrm{C}, 1 \mathrm{~min} ; 75^{\circ} \mathrm{C}$, $1 \mathrm{~min} ; 65^{\circ} \mathrm{C}, 1 \mathrm{~min} ; 55^{\circ} \mathrm{C}, 1 \mathrm{~min} ; 45^{\circ} \mathrm{C}, 1 \mathrm{~min} ; 35^{\circ} \mathrm{C}, 1$ $\min ; 25^{\circ} \mathrm{C}, 1 \mathrm{~min}$ (the temperature ramping between each step was set at $-1^{\circ} \mathrm{C} / \mathrm{sec}$ ); hold at $4^{\circ} \mathrm{C}$. Hybridized PCR products were treated with $1 \mu \mathrm{l}$ of Enhancer and $1 \mu \mathrm{l}$ of Surveyor endonuclease (IDT) at $42^{\circ} \mathrm{C}, 40 \mathrm{~min}$. Reactions were stopped by the addition of $1.5 \mu \mathrm{l}$ of the Stop solution (provided by the Surveyor kit) and digestion products were visualized on $10 \%$ TBE Acrylamide gel. Mutations at target sites were then confirmed using Sanger sequencing and deep targeted next generation sequencing.

\section{Sanger sequencing of mutant alleles}

The target region of $M A P 3 K 1$ gene from each clone was amplified and purified using QIAGEN PCR purification kit following the manufacturer's instruction. Purified fragments were then A-tailed using Ampli-Taq DNA polymerase kit (Roche) at $72^{\circ} \mathrm{C}, 30 \mathrm{~min}$ and were cloned into PCR2.1 TOPO vector using a Topo cloning kit and transformed into One-Shot E. coli competent cells (Life Technologies). Plasmid DNA was isolated for at least 5 colonies from each transformation and then sequenced using M13Fwd primer.

\section{Targeted deep next generation sequencing (NGS)}

The MAP $3 K 1$ knockout cells were further confirmed using NGS. Briefly, the targeted MAP3K1 site was amplified using Fusion-Flash HiFi DNA polymerase (Life Technologies) using the primers listed in Supplementary Table 1. PCR products were generated from 50ng of genomic DNA extracted from wild-type and knockout cells. Amplified PCR products were subjected to pairedend sequencing using a NextSeq500 NGS instrument (Illumina). Finally, sequencing reads were automatically de-multiplexed using NextSeq500 Instrument and paired FASTQ files were analyzed using CRISPResso [44]. The frequency of mutated alleles among NGS reads were calculated based on the CRISPResso's detected alleles (Supplementary Figure 1).

\section{siRNA targeting}

Cells were transiently transfected using Lipofectamine RNAiMax (Invitrogen, Grand Island, NY,
USA). siRNA SMARTpool from Dharmacon (Lafayette, CO, USA) was purchased for targeting MAP $3 K 1$ while a silencer negative control from Ambion (Grand Island, NY, USA) was used as a negative control. Transfections of siRNA MAP3K1 oligonucleotides were performed in six-well plates at a final concentration of $10 \mathrm{nM}$ siRNA oligonucleotides and incubated for 48 hours according to the manufacturer's instructions.

\section{Confocal microscopy}

Alexa Fluor 488 or 594 conjugated secondary antibodies (Thermo Fisher Scientific, MA, US) were used for 3D culture immunofluorescence assays. MCF10API3Ka $\alpha^{\mathrm{H} 1047 \mathrm{R}} 3 \mathrm{D}$-acini were fixed (4\% PFA) at day 15 and processed for immunofluorescence microscopy analysis as established previously [59]. Confocal analyses were performed using the Leica SP5 Multi-photon confocal microscope equipped with UV diode (405 nm), argon (458, 476,488 and $514 \mathrm{~nm}), \mathrm{HeNe}(543 \mathrm{~nm})$ and a HeNe $(633 \mathrm{~nm})$ lasers. All images were obtained with a x63 objective. Quantitative measurements of optical density were performed with ImageJ (National Institutes of Health, US). Acinar size was calculated with LAS X software (Leica) following the equation [(length $\times$ width $\left.^{2}\right) / 2=$ acini volume $\left.\left(\mathrm{mm}^{3}\right)\right]$ and plotted with GraphPad Prism.

\section{Immuno-histochemistry}

The immunostaining protocol was performed as described previously [60]. In summary, sections were dewaxed in 2 changes of xylene, 2 changes of absolute alcohol and 1 change of $70 \%$ alcohol. Antigen retrieval was performed in $\mathrm{pH} 6$ buffer and heated to pressure at $110^{\circ} \mathrm{C}$, for 2 minutes. Slides were subsequently processed on the Labvision Autostainer for peroxidise blocking (3\%), serum block (Dako X0909), primary antibody incubation (cleaved caspase 3 diluted 1:250 and p-Rb, p-S6 RP and p-IRS1 diluted 1:200), secondary Ab incubation (Dako Envision+/ HRP) and final liquid DAB+ (Dako K3468) incubation.

\section{Statistics}

Statistical analyses were performed using GraphPad Prism 5.0 software (GraphPad software) and P-values were calculated using one-way analysis of variance followed by the Bonferroni multiple comparison post-test or the unpaired Student's $t$-test with $\mathrm{P}<0.05$ considered statistically significant; N.S., not significant. Mannwhitney $\mathrm{u}$ test was used for the non-normal distributions (in vivo data).

\section{ACKNOWLEDGMENTS}

AZD5363 was discovered by AstraZeneca subsequent to a collaboration with Astex Therapeutics 
(and its collaboration with the Institute of Cancer Research and Cancer Research Technology Limited).

We would like to thank Joe Gerrard and Vidalba Rocher-Ros from the Translational Sciences team for their help with the histology samples preparation and HALO analysis and Lenka Oplustil O'Connor from the Bioscience Department for her assistance with cell sorting. We also want to thank Edouard Riey for his help with western blot analysis. Likewise, we would like to acknowledge the help of Natalie Metcalfe, Dave Simpson and Mark Hall from the LAS team and Urs Yelland from the in vivo group.

\section{CONFLICTS OF INTEREST}

All authors are current or former employees of AstraZeneca. K. Hudson and F Cruzalegui have ownership interest (including patents) and are AstraZeneca shareholders. No potential conflicts of interest were disclosed by the other authors.

\section{FUNDING}

This study was sponsored by the AstraZeneca postdoctoral program.

\section{REFERENCES}

1. Polyak K. Heterogeneity in breast cancer. J Clin Invest. 2011; 121:3786-8.

2. Zardavas D, Irrthum A, Swanton C, Piccart M. Clinical management of breast cancer heterogeneity. Nat Rev Clin Oncol. 2015; 12:381-94.

3. Cancer Genome Atlas N. Comprehensive molecular portraits of human breast tumours. Nature. 2012; 490:61-70.

4. Ellis MJ, Ding L, Shen D, Luo J, Suman VJ, Wallis JW, Van Tine BA, Hoog J, Goiffon RJ, Goldstein TC, Ng S, Lin L, Crowder R, et al. Whole-genome analysis informs breast cancer response to aromatase inhibition. Nature. 2012; 486:353-60.

5. Stephens PJ, Tarpey PS, Davies H, Van Loo P, Greenman C, Wedge DC, Nik-Zainal S, Martin S, Varela I, Bignell GR, Yates LR, Papaemmanuil E, Beare D, et al. The landscape of cancer genes and mutational processes in breast cancer. Nature. 2012; 486:400-4.

6. Abreu-Martin MT, Chari A, Palladino AA, Craft NA, Sawyers CL. Mitogen-activated protein kinase kinase kinase 1 activates androgen receptor-dependent transcription and apoptosis in prostate cancer. Mol Cell Biol. 1999; 19:5143-54

7. Charlaftis N, Suddason T, Wu X, Anwar S, Karin M, Gallagher E. The MEKK1 PHD ubiquitinates TAB1 to activate MAPKs in response to cytokines. EMBO J. 2014; $33: 2581-96$
8. Nelson DS, van Halteren A, Quispel WT, van den Bos C, Bovee JV, Patel B, Badalian-Very G, van Hummelen P, Ducar M, Lin L, MacConaill LE, Egeler RM, Rollins BJ. MAP2K1 and MAP3K1 mutations in Langerhans cell histiocytosis. Genes Chromosomes Cancer. 2015; 54:361-8.

9. Suddason T, Gallagher E. A RING to rule them all? Insights into the Map3k1 PHD motif provide a new mechanistic understanding into the diverse roles of Map3k1. Cell Death Differ. 2015; 22:540-8.

10. Cuevas BD, Winter-Vann AM, Johnson NL, Johnson GL. MEKK1 controls matrix degradation and tumor cell dissemination during metastasis of polyoma middle-T driven mammary cancer. Oncogene. 2006; 25:4998-5010.

11. Hirano T, Shino Y, Saito T, Komoda F, Okutomi Y, Takeda A, Ishihara T, Yamaguchi T, Saisho H, Shirasawa H. Dominant negative MEKK1 inhibits survival of pancreatic cancer cells. Oncogene. 2002; 21:5923-8.

12. Pham TT, Angus SP, Johnson GL. MAP3K1: genomic alterations in cancer and function in promoting cell survival or apoptosis. Genes Cancer. 2013; 4:419-26. https://doi. org/10.1177/1947601913513950.

13. Hagemann C, Blank JL. The ups and downs of MEK kinase interactions. Cell Signal. 2001; 13:863-75.

14. Lu Z, Xu S, Joazeiro C, Cobb MH, Hunter T. The PHD domain of MEKK1 acts as an E3 ubiquitin ligase and mediates ubiquitination and degradation of ERK1/2. Mol Cell. 2002; 9:945-56.

15. Xia Y, Wang J, Xu S, Johnson GL, Hunter T, Lu Z. MEKK1 mediates the ubiquitination and degradation of c-Jun in response to osmotic stress. Mol Cell Biol. 2007; 27:510-7.

16. Schlesinger TK, Bonvin C, Jarpe MB, Fanger GR, Cardinaux JR, Johnson GL, Widmann C. Apoptosis stimulated by the $91-\mathrm{kDa}$ caspase cleavage MEKK1 fragment requires translocation to soluble cellular compartments. J Biol Chem. 2002; 277:10283-91.

17. Bonvin C, Guillon A, van Bemmelen MX, Gerwins P, Johnson GL, Widmann C. Role of the amino-terminal domains of MEKKs in the activation of NF kappa B and MAPK pathways and in the regulation of cell proliferation and apoptosis. Cell Signal. 2002; 14:123-31.

18. Lee FS, Peters RT, Dang LC, Maniatis T. MEKK1 activates both IkappaB kinase alpha and IkappaB kinase beta. Proc Natl Acad Sci U S A. 1998; 95:9319-24.

19. Lange-Carter CA, Pleiman CM, Gardner AM, Blumer KJ, Johnson GL. A divergence in the MAP kinase regulatory network defined by MEK kinase and Raf. Science. 1993; 260:315-9.

20. Minden A, Lin A, Smeal T, Derijard B, Cobb M, Davis R, Karin M. c-Jun N-terminal phosphorylation correlates with activation of the JNK subgroup but not the ERK subgroup of mitogen-activated protein kinases. Mol Cell Biol. 1994; 14:6683-8

21. Park HS, Kim MS, Huh SH, Park J, Chung J, Kang SS, Choi EJ. Akt (protein kinase B) negatively regulates SEK1 
by means of protein phosphorylation. J Biol Chem. 2002; 277:2573-8.

22. Aguirre V, Uchida T, Yenush L, Davis R, White MF. The c-Jun $\mathrm{NH}(2)$-terminal kinase promotes insulin resistance during association with insulin receptor substrate-1 and phosphorylation of Ser(307). J Biol Chem. 2000; 275:9047-54.

23. Hiratani K, Haruta T, Tani A, Kawahara J, Usui I, Kobayashi M. Roles of mTOR and JNK in serine phosphorylation, translocation, and degradation of IRS-1. Biochem Biophys Res Commun. 2005; 335:836-42.

24. Lee YH, Giraud J, Davis RJ, White MF. c-Jun N-terminal kinase (JNK) mediates feedback inhibition of the insulin signaling cascade. J Biol Chem. 2003; 278:2896-902.

25. Manning BD. Balancing Akt with S6K: implications for both metabolic diseases and tumorigenesis. J Cell Biol. 2004; 167:399-403.

26. Shi Y, Yan H, Frost P, Gera J, Lichtenstein A. Mammalian target of rapamycin inhibitors activate the AKT kinase in multiple myeloma cells by up-regulating the insulinlike growth factor receptor/insulin receptor substrate-1/ phosphatidylinositol 3-kinase cascade. Mol Cancer Ther. 2005; 4:1533-40.

27. Hudson K, Hancox UJ, Trigwell C, McEwen R, Polanska UM, Nikolaou M, Morentin Gutierrez P, Avivar-Valderas A, Delpuech O, Dudley P, Hanson L, Ellston R, Jones A, et al. Intermittent high-dose scheduling of AZD8835, a novel selective inhibitor of PI3Kalpha and PI3Kdelta, demonstrates treatment strategies for PIK3CA-dependent breast cancers. Mol Cancer Ther. 2016; 15:877-89.

28. Addie M, Ballard P, Buttar D, Crafter C, Currie G, Davies BR, Debreczeni J, Dry H, Dudley P, Greenwood R, Johnson PD, Kettle JG, Lane C, et al. Discovery of 4-amino-N-[(1S)1-(4-chlorophenyl)-3-hydroxypropyl]-1-(7H-pyrrolo[2,3-d] pyrimidin-4-yl)piperidine-4-carboxamide (AZD5363), an orally bioavailable, potent inhibitor of Akt kinases. J Med Chem. 2013; 56:2059-73.

29. Davies BR, Greenwood H, Dudley P, Crafter C, Yu DH, Zhang J, Li J, Gao B, Ji Q, Maynard J, Ricketts SA, Cross D, Cosulich S, et al. Preclinical pharmacology of AZD5363, an inhibitor of AKT: pharmacodynamics, antitumor activity, and correlation of monotherapy activity with genetic background. Mol Cancer Ther. 2012; 11:873-87.

30. Aguirre V, Werner ED, Giraud J, Lee YH, Shoelson SE, White MF. Phosphorylation of Ser307 in insulin receptor substrate-1 blocks interactions with the insulin receptor and inhibits insulin action. J Biol Chem. 2002; 277:1531-7.

31. Tanti JF, Gual P, Gremeaux T, Gonzalez T, Barres R, Le Marchand-Brustel Y. Alteration in insulin action: role of IRS-1 serine phosphorylation in the retroregulation of insulin signalling. Ann Endocrinol (Paris). 2004; 65:43-8.

32. Fruman DA, Rommel C. PI3K and cancer: lessons, challenges and opportunities. Nat Rev Drug Discov. 2014; $13: 140-56$.
33. Jimenez C, Hernandez C, Pimentel B, Carrera AC. The p85 regulatory subunit controls sequential activation of phosphoinositide 3-kinase by Tyr kinases and Ras. J Biol Chem. 2002; 277:41556-62.

34. Carracedo A, Pandolfi PP. The PTEN-PI3K pathway: of feedbacks and cross-talks. Oncogene. 2008; 27:5527-41.

35. Skolnik EY, Lee CH, Batzer A, Vicentini LM, Zhou M, Daly R, Myers MJ Jr, Backer JM, Ullrich A, White MF, Schlessinger J. The SH2/SH3 domain-containing protein GRB2 interacts with tyrosine-phosphorylated IRS1 and Shc: implications for insulin control of ras signalling. EMBO J. 1993; 12:1929-36.

36. Hebner C, Weaver VM, Debnath J. Modeling morphogenesis and oncogenesis in three-dimensional breast epithelial cultures. Annu Rev Pathol. 2008; 3:313-39.

37. Debnath J, Muthuswamy SK, Brugge JS. Morphogenesis and oncogenesis of MCF-10A mammary epithelial acini grown in three-dimensional basement membrane cultures. Methods. 2003; 30:256-68.

38. Debnath J, Brugge JS. Modelling glandular epithelial cancers in three-dimensional cultures. Nat Rev Cancer. 2005; 5:675-88.

39. Avivar-Valderas A, Bobrovnikova-Marjon E, Alan Diehl J, Bardeesy N, Debnath J, Aguirre-Ghiso JA. Regulation of autophagy during ECM detachment is linked to a selective inhibition of mTORC1 by PERK. Oncogene. 2013; 32:4932-40.

40. Avivar-Valderas A, Salas E, Bobrovnikova-Marjon E, Diehl JA, Nagi C, Debnath J, Aguirre-Ghiso JA. PERK integrates autophagy and oxidative stress responses to promote survival during extracellular matrix detachment. Mol Cell Biol. 2011; 31:3616-29.

41. Avivar-Valderas A, Wen HC, Aguirre-Ghiso JA. Stress signaling and the shaping of the mammary tissue in development and cancer. Oncogene. 2014; 33:5483-90.

42. Wen HC, Avivar-Valderas A, Sosa MS, Girnius N, Farias EF, Davis RJ, Aguirre-Ghiso JA. p38alpha signaling induces anoikis and lumen formation during mammary morphogenesis. Sci Signal. 2011; 4:ra34.

43. Schedin P, Elias A. Multistep tumorigenesis and the microenvironment. Breast Cancer Res. 2004; 6:93-101.

44. Pinello L, Canver MC, Hoban MD, Orkin SH, Kohn DB, Bauer DE, Yuan GC. Analyzing CRISPR genome-editing experiments with CRISPResso. Nat Biotechnol. 2016; 34:695-697.

45. Guo W, Giancotti FG. Integrin signalling during tumour progression. Nat Rev Mol Cell Biol. 2004; 5:816-26.

46. Ossowski L, Aguirre-Ghiso JA. Urokinase receptor and integrin partnership: coordination of signaling for cell adhesion, migration and growth. Curr Opin Cell Biol. 2000; 12:613-20.

47. Minamino T, Yujiri T, Terada N, Taffet GE, Michael LH, Johnson GL, Schneider MD. MEKK1 is essential for 
cardiac hypertrophy and dysfunction induced by Gq. Proc Natl Acad Sci U S A. 2002; 99:3866-71.

48. Zechner D, Thuerauf DJ, Hanford DS, McDonough PM, Glembotski CC. A role for the p38 mitogen-activated protein kinase pathway in myocardial cell growth, sarcomeric organization, and cardiac-specific gene expression. J Cell Biol. 1997; 139:115-27.

49. Dienstmann R, Rodon J, Serra V, Tabernero J. Picking the point of inhibition: a comparative review of PI3K/ AKT/mTOR pathway inhibitors. Mol Cancer Ther. 2014; 13:1021-31.

50. Gual P, Le Marchand-Brustel Y, Tanti JF. Positive and negative regulation of insulin signaling through IRS-1 phosphorylation. Biochimie. 2005; 87:99-109.

51. Cuevas BD, Lu Y, Mao M, Zhang J, LaPushin R, Siminovitch K, Mills GB. Tyrosine phosphorylation of p85 relieves its inhibitory activity on phosphatidylinositol 3-kinase. J Biol Chem. 2001; 276:27455-61.

52. Lee JY, Chiu YH, Asara J, Cantley LC. Inhibition of PI3K binding to activators by serine phosphorylation of PI3K regulatory subunit p85alpha Src homology-2 domains. Proc Natl Acad Sci U S A. 2011; 108:14157-62.

53. Kennedy SG, Wagner AJ, Conzen SD, Jordan J, Bellacosa A, Tsichlis PN, Hay N. The PI 3-kinase/Akt signaling pathway delivers an anti-apoptotic signal. Genes Dev. 1997; 11:701-13.

54. Kolch W, Halasz M, Granovskaya M, Kholodenko BN. The dynamic control of signal transduction networks in cancer cells. Nat Rev Cancer. 2015; 15:515-27.
55. McCubrey JA, Steelman LS, Chappell WH, Abrams SL, Montalto G, Cervello M, Nicoletti F, Fagone P, Malaponte G, Mazzarino MC, Candido S, Libra M, Basecke J, et al. Mutations and deregulation of Ras/Raf/MEK/ ERK and PI3K/PTEN/Akt/mTOR cascades which alter therapy response. Oncotarget. 2012; 3:954-87. https://doi. org/10.18632/oncotarget.652.

56. Caunt CJ, Sale MJ, Smith PD, Cook SJ. MEK1 and MEK2 inhibitors and cancer therapy: the long and winding road. Nat Rev Cancer. 2015; 15:577-92.

57. Balkwill FR, Capasso M, Hagemann T. The tumor microenvironment at a glance. J Cell Sci. 2012; 125:5591-6.

58. Fluegen G, Avivar-Valderas A, Wang Y, Padgen MR, Williams JK, Nobre AR, Calvo V, Cheung JF, BravoCordero JJ, Entenberg D, Castracane J, Verkhusha V, Keely PJ, et al. Phenotypic heterogeneity of disseminated tumour cells is preset by primary tumour hypoxic microenvironments. Nat Cell Biol. 2017; 19:120-32.

59. Sequeira SJ, Ranganathan AC, Adam AP, Iglesias BV, Farias EF, Aguirre-Ghiso JA. Inhibition of proliferation by PERK regulates mammary acinar morphogenesis and tumor formation. PLoS One. 2007; 2:e615.

60. Smith NR, Womack C. A matrix approach to guide IHCbased tissue biomarker development in oncology drug discovery. J Pathol. 2014; 232:190-8. 